Practical Points in Eye Surgery and Dressing. By HUGH E. JoNES, M.R.C.S.(Eng.), L.R.C.P.(Lond.). Pp. 21, 3 charts. London: John Bale, Sons and Danielsson. 1933. Price, 2s. 6d.

The author has intended this little book for the use of general practitioners attending eye cases in Cottage Hospitals, housesurgeons new to ophthalmology and nurses in charge of eye patients. It contains useful practical information about the examination of ophthalmic cases and their immediate treatment prior to being seen by the "specialist." The author points out the serious consequences that delay, inefficient treatment and lack of preparation for the administrations of the ophthalmic surgeon may cause to eye patients who present themselves at hospitals where the immediate services of an ophthalmic surgeon are not always available.

The author makes no attempt to describe at length diseases of the eye but confines his remarks to the examination and immediate treatment of common eye injuries and urgent non-traumatic conditions such as muco-purulent conjunctivitis, hypopyon ulcer, acute iritis, acute glaucoma, keratitis, lacrymal abscess and a few other diseases.

Part of the book is devoted to a description of the preparation of patients for eye operations, the sterilization and care of instruments, anaesthetics, post-operative complications and convalescence.

In a pocket at the end of the book there are three tables to which a casualty officer or nurse can refer quickly for information about urgent non-traumatic eye cases, common eye injuries, and operations. In a tabular form details about the methods of examination, clinical signs, treatment, instruments required, pre-operative and postoperative care, nursing and convalescence are briefly given.

\title{
CORRESPONDENCE
}

\section{THE RETINAL VISUAL CELLS IN MAN AND IN FRESH-WATER FISH}

To the Editors of The BRITISH Journal of Ophthalmology.

SiRS,-Mr. M. S. Mayou's paper on: "The Retinal Visual Cells in Man and in Fresh-water Fish" has recently come to my attention, and I feel impelled to bring to attention certain errors therein, which, if allowed to stand, will lead to misconceptions of the comparative histology of the retina.

Mr. Mayou seems to doubt the validity of the Duplicity Theory, but I know of no single point against it. Arguments against the 
theory usually take the form of insistence that such and such a form has colour-vision yet has no cones (e.g., Walton, 1933) or has a Purkinje phenomenon and yet has no rods (e.g., Hess, 1910). In all such cases either the histological conception or the technique of examination for colour-vision is at fault. The physiological differences between rods and cones are so wide that there are actually cases where animals have been forced to transform one type of cell into the other, phylogenetically, in order to change their light-habits; this transmutation process will be explained and illustrated in a paper to appear in a year or so.

"The subject of retinology is by no means "chaotic" if only one takes into consideration the difference in technical quality of past and present work, which accounts for so many seeming contradictions in the literature. The investigations of Cameron and Bernard, which Mr. Mayou refers to extensively, are among the most unfortunate ever made - not so much because they are so full of ludicrous errors, but because the two investigations were made absolutely independently and yet arrived at the same set of conclusions. Neither Mr. Mayou nor any one else unfamiliar with the entire literature can be blamed for assuming that Cameron's and Bernard's ideas must be correct, since they are corroborative of each other.

It is absolutely untrue that the rods and cones in fishes "are not differentiated as they are in man." The simple comparison of Mr. Mayou's figures with, say, Fig. 18 of Garten (1907) will show at once that Mr. Mayou has failed to recognize the rods in his Teleost material. In the legend of his Fig. 9, he implies that the only cone-like cells in the frog are rods which have been "cut on the bias"; this in the face of Fig. 31 of Greeff (1900) and other representations of frog visual cells which show two types of rods and three distinct types of cones. In his text, Mr. Mayou similarly implies that the only rod-like cells in Teleosts are cones whose outer segments have blunt points.

Mr. Mayou has not only overlooked the huge numbers of little rods in his Teleosts, but has failed to note that about half of the cones are of the "twin" type, well shown in Fig. 37 of Franz (1913). It is these which, in Mr. Mayou's Fig. 13, have migrated beyond the single cones and which he suggests are homologous with human rods.

The discussion of development is largely based upon Cameron and Bernard, who used such atrocious fixatives that the appearances they obtained are utterly meaningless. Cones are not conical simply so that they may intrude the more easily between the rods, nor do they ever develop into rods through such intermediate stages as Bernard's figures show. Bernard supposed that the "bag of fluid" at the tip of the cone outer segment became filled with solid 
material and converted into a rod outer segment. The outer segment of the cone is a "bag of fluid" only when, as in Bernard's technique, it is subjected to boiling. Frogs do not show more rods and fewer cones, the older they get !

Visual cells are not designated as rods or cones solely upon the shape of the outer segment or upon the shape of the ellipsoid, but on the following bases to which some other investigators would add still other criteria :-

Rods :

Connected in multiple to bipolar neurons.

Outer segment of maximal volume in order to carry on maximum photochemical activity, and therefore cylindrical.

Contain visual purple when darkadapted.

Elongate in light and contract in darkness, if they move at all.

Predominate in nocturnal animals, sometimes to the exclusion of cones.

Often have a compact end-knob devoid of lateral branches.

Never contain coloured oil-droplets.

Never doubled unless secondarily formed from double cones (geckoes and two or three snakes).

Nuclear chromatin often in large pieces without linin.

Usually have the nucleus below the limitans.

\section{Cones:}

Connected singly, or nearly so, to bipolars.

Outer segment of minimal volume, and thus conical unless inner segment is filamentous, as in Muridae.

Never contain visual purple.

Elongate in darkness and contract in light, if they move at all.

Predominate in diurnal animals, sometimes to the exclusion of rods.

Always have a dendritic end-knob.

Often contain coloured oil - droplets.

Double or twin cones in all but lampreys and mammals.

Nuclear chromatin always in small pieces, on linin network.

Usually have the nucleus in contact with limitans.

The few exceptions to any of these rules never make it even difficult to distinguish rods from cones where both are present; and contrary to Mr. Mayou's assertion, most retinae contain both. In fact, the only retinae known beyond any question to contain only rods are those of coecilians, geckoes, one or two snakes, bats and deep-sea fishes. The only retinae unquestionably pure-cone are those of round-pupilled snakes and lizards, one or two birds, and marmots. In all other cases the ratio of rod and cone substance, the amount of neurological summation, the amount of sensitizing pigment (visual purple), and the degree of development of intraocular colour-filters go precisely with the leanings of the animal 
toward nocturnality, diurnality, or indifference. Apart from its colour-vision tenet, no theory in all physiology is on a firmer basis than the Duplicity Theory.

Lastly, in Fig 6, Mr. Mayou has identified the parts of the cones of the Dace in exactly the reverse order. The portions labelled "outer members" are the foot-pieces which connect with bipolar cells-as nicely brought out as I have ever seen them. His " ellipsoid" is the nucleus, which is ectopic in Teleost cones; his "myoid" is the ellipsoid, and the wriggly appendage of the righthand cone is a shrivelled outer segment.

Mr. Mayou is quite correct in emphasizing the inestimable value of Mallory's triple stain, which I have employed for retinae for eight years with great success. His ideas upon fixatives, however, carry us back to the middle of the last century; the fixative par excellence for the majority of retinae is Kolmer's fluid.

The publications I have cited are as follows :-

Franz, V. (1913) Sehorgan. In: Oppel's "Lehrbuch der vergleichenden mikroskopischen Anatomie," Teil 7.

Garten, S. (1907). Die Veränderungen der Netzhaut durch Licht. In : GraefeSaemisch "Handbuch der gesamte Augenheilkunde," 2te Aufl., Bd. III, Kap. 12, Anhang.

Greeff, R. (1900). Die mikroskopische Anatomie des Sehnerven und der Netzhaut, Ibid., Bd. I, Kap. 5.

Hess, C. (1910). Untersuchungen über den Lichtsinn bei Reptilien und Amphibien. Arch.f.d ges. Physiol., Vol. CXXXII, pp. 255-295.

Walton, W. E. (1933). Colour vision and colour preference in the albino rat. Journ. Comp. Psychol., Vol. XV, pp. 359-394.

\author{
GORDON L. WALLS, \\ Museum of Zoology, University of \\ Michigan, Ann Arbor.
}

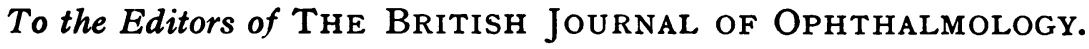

SIRS,-In Dr. Luther Peter's paper read before the Oxford Congress and recently published, several erroneous statements are made concerning my cinch shortening operation due, most likely, to a lack of extended experience with the method. In fairness to the operation I feel that those who heard or who have read the paper should be set straight.

The statements I object to are :-

1. His idea of the indications for its use.

2. The constancy of excessive reactions.

3. The occurrence of adhesions between tendon and sclera.

The writer feels that his experience extending over twenty-two years and approximately two thousand operations qualifies him to make very definite statements concerning the operation and any 
mishap that may occur. He has had them all, except loss of an eye or any impairment of vision, in working it up to its present position and feels that he has worked out the solutions for most of them.

1. Concerning indications for its use. Being a form of tendon shortening I can see no reason why it is not indicated in all cases where such a result is desired. Even more than other tendon shortening methods because of the certain and positive nature of its mechanics. . For this same reason it can be used more safely in phorias and in insufficiency of convergence.

2. Concerning the constancy of excessive reactions. In the absence of infection these are rare in my experience. Why others have them I do not know-never having seen anyone else do my operation. Some operators use too many shortening strands thus making a large amount of foreign substance to set up irritation. Some use sub-conjunctival anesthetic injections which may cause disturbance. Frequently patients operated on by me on Saturday go to school or back to work on Monday. Many superior rectus shortenings wear no dressing at all and go about as though nothing had happened. This is done to favour binocular balance and not as a "stunt."

Infections have been rare since I have used rubber dam mounted on the speculum to protect the shorteners from contamination by the lids and lashes. Contrary to Dr. Peter's ideas I have felt that the shorteners act as capillary drains to the tendon and thus lessen the chance of infection. In general surgery a capillary drain to an infected area when covered by a moist dressing tends to remove serum and pus as it forms. Why should this principle of action be reversed in connection with my operation?

3. Concerning the occurrence of adhesions between the sclera and point of shortening. In a personal letter to Dr. Peter explaining that this does not occur and that its absence is one of my chief claims I asked if he had seen such an occurrence or if his opinion was purely theoretical. He replied that he had not seen it but that he knew it must occur. Many times I have reshortened tendons and have yet to find such an adhesion. The adhesions are all in the tendon and render very difficult the making of strips for shortening. I have always felt that the normal action of the eyes and muscles prevents their formation between sclera and tendon.

Naturally I feel that actual experience in this, as well as in the other points mentioned, is superior to theoretical assumptions based on experiences with entirely different types of shortenings.

$$
\text { Yours truly, }
$$

RODERICK O'CONNOR.

San Francisco. 
To the Editors of The BRITISH JOURnal OF Ophthalmology.

SIRS,-In the July number of this year appeared an article by Krishnaswami, "A New Anterior Synechia Knife." The anterior chamber is opened with a keratome, and the anterior synechia severed with a knife needle, which is rounded on the point. $\mathrm{Mr}$. Krishnaswami evidently is not aware of the fact, that this very same proceeding was used by Mr. Lang, of Moorfields, in the early 90 's of the last century. I saw him perform the operation at least 45 years ago, bought a set of his knife needles, the one pointed the other blunt, at J. Weiss \& Son, and have used them a good many times with success.

Yours very truly,

CARL KOLLER.

NEW YORK.

The needle in question is not quite similar to that of Lang's blunt knife in that the latter is sharp on one edge only.-EDITORS.

\section{OBITUARY}

\section{E. DYKES BOWER, M.D.}

WE regret to record the death on September 16, of Dr. Ernest Dykes Bower, of Gloucester, in his eightieth year. Descended from the celebrated William Hey, of Leeds, he was born at that city in 1853, and educated at the Leeds Grammar School and Leeds General Infimary. In 1874 he spent six months in Oxford as Radcliffe student, and having qualified in 1875, he was House Surgeon at Leeds to Pridgin Teale and Wheelhouse. He then was elected House Surgeon at Gloucester Royal Infirmary, and after holding this post for 3 years he settled in Gloucester and was soon elected Ophthalmic Surgeon to the Infirmary, and later Hon. Surgeon to that Institution.

$\mathrm{He}$ was much respected in Gloucester and its surroundings and was High Sheriff of the City in 1910. He was a Member of the Ophthal. Soc. of the U.K., 1885-1927.

Dykes Bower came of a musical family, the Rev. J. B. Dykes, author of some of the most beautiful tunes in "Hymns, Ancient and Modern," having been his cousin. He himself was in younger days a very fine organist, his touch upon the piano was delightful, and he 